\title{
JUDICIALIZAÇÃO, CORPORATIVISMO E AUTORITARISMO NA CRISE DA DEMOCRACIA BRASILEIRA
}

JUDICIALIZATION, CORPORATISM AND AUTHORITARIANISM IN THE CRISIS OF BRAZILIAN DEMOCRACY

\section{Valdemar F. de Araújo Filho}

Sociólogo pela Universidade Federal da Bahia (UFBA)e professor do Departamento de Ciência Política da mesma universidade. Mestre em Planejamento Urbano e Regional pela Universidade Federal do Rio de Janeiro (UFRJ). Tem doutorado em Ciência Política pelo Instituto Universitário de Pesquisas do Rio de Janeiro (IUPERJ) e pós-doutorado em Ciência Política pela Universidade de Salamanca.

\section{Pedro de Araújo Fernandes}

Advogado, mestre pela Pontifícia Universidade Católica do Rio de Janeiro (PUC-RIO) e doutorando em Ciência Política pelo Instituto de Estudos Sociais e Políticos da Universidade do Estado do Rio de Janeiro (IESP/UERJ). Integra o Núcleo de Pesquisas em Direito e Ciências Sociais (DECISO), o Grupo de Estudos de Economia e Política (GEEP) e o Núcleo de Estudos Sobre o Congresso (NECON). 


\section{RESUMO}

O artigo aborda a crise da democracia brasileira com foco no papel do sistema de Justiça. Incialmente, o texto situa a crise em um contexto histórico mais amplo, que remonta às raízes elitistas e oligárquicas da própria instauração da república no Brasil, desdobradas, a partir dos anos 1930, em um corporativismo estatal que foi renovado nos governos recentes. Argumenta-se que essa lógica corporativista se estendeu, durante os governos petistas, às instituições que compõem o sistema de Justiça. Tais instituições, em especial o Ministério Público, dotadas de grande autonomia e sem estarem submetidas ao controle democrático, alçaram o combate à corrupção ao principal valor simbólico e moral do país, gerando profundo desgaste na legitimidade do sistema representativo e fragilizando os princípios políticos orientadores da democracia. Conclui-se que essas instituições tiveram papel determinante no impeachment de Dilma Rousseff, em 20I6, e na pavimentação do caminho que levou à vitória de Jair Bolsonaro, em 20I8, contribuindo, portanto, para a atual crise democrática no país.

Palavras-chave: democracia; corporativismo; judicialização; sistema de justiça.

\section{ABSTRACT}

The article examines the crisis of Brazilian democracy with a focus on the justice system. The crisis is situated in a broader historical context, that connects to the elitist and oligarchic roots of the Brazilian republic, and to the state corporatism of the I930s, wich was renewed in recent governments. It is argued that this corporatist logic was extended to the justice system during PT governments. In this context, the fight against corruption became the moral imperative of the republic, weakening the legitimacy of the representative system and the political principles of the Brazilian democracy. On conclusion the justice system played a decisive role in the impeachment of Dilma Rousseff in 2016 and in Jair Bolsonaro's victory in 2018, thus contributing to the current democratic crisis in the country.

Keywords: democracy; corporatism; judicialization; justice system. 


\section{O contexto da crise atual e a natureza da trajetória da república}

A crise da democracia brasileira nos anos recentes tem sido objeto de inúmeros estudos nas ciências sociais. O impeachment da ex-presidenta Dilma Rousseff, em 20I6, e a eleição de Jair Bolsonaro, em 20I8, candidato da extrema direita eleito com um discurso autoritário e orientado para a negação da política, se situaram como marcos políticos significativos dessa crise, sinalizando para os rumos erráticos que o sistema político assumiria nos três anos subsequentes à campanha presidencial de 2018.

O espaço aberto pelas recentes inflexões nos tradicionais padrões institucionais do processo político instaurado desde o advento da Nova República propiciou as condições para o surgimento de iniciativas até então observadas no universo da ficção política, a exemplo da grande mobilização de massa deflagrada pelo Chefe do Poder Executivo, no dia o7 de setembro de 202I, quando o próprio presidente Bolsonaro vocalizou ameaças contra membros do Supremo Tribunal Federal (STF) diante de multidões que clamavam por intervenção militar. Mas esse foi apenas um dos muitos eventos mobilizados pelo presidente desde a posse, que, na prática, tem se dedicado mais a ações de mobilização política do que a iniciativas administrativas concretas. Rigorosamente, o presidente não coordena o aparato burocrático administrativo do Poder Executivo: enquanto delega aos escalões superiores do Executivo os aspectos administrativos rotineiros de governo, mobiliza pessoalmente segmentos do eleitorado para a manutenção de um permanente estado de mobilização política radicalizada no país.

Nesse contexto, tem emergido a discussão sobre o "funcionamento das instituições", que poderia ser traduzido como de natureza bizantina se não fosse perceptível a postura de conciliação ou de leniência das lideranças institucionais da república diante do voluntarismo político do presidente Bolsonaro, lideranças estas que deveriam zelar pela manutenção da ordem constitucional republicana. A resposta padrão que tem predominado dentro do establishment político e entre analistas da política na mídia, "as instituições estão funcionando", na verdade revela uma postura conservadora diante da natureza crescentemente elitista da democracia e do processo de oligarquização da república, fenômenos que se aceleraram desde a ruptura institucional de 2016.

De fato, se os frequentes arroubos autoritários de Bolsonaro têm encontrado limites pontuais em instituições da república, essa constante testagem política das instituições tem revelado que tanto as lideranças do Judiciário quanto do Legislativo não têm dado a devida atenção às consequências políticas e institucionais derivadas do processo de flexibilização das fronteiras internas do sistema político para a estabilidade e a institucionalização da democracia. Reações institucionais mais incisivas têm acontecido por iniciativa do Judiciário e do Legislativo quando as mobilizações do presidente ameaçam deslegitimar politicamente 
um desses Poderes ou seus privilégios corporativos. Em contrapartida, condizente com a tradição elitista e corporativista do sistema político brasileiro, essas mesmas instituições adotam uma postura conciliatória quando princípios de proteção social e de direitos trabalhistas cristalizados no pacto constitucional de 1988 são constantemente flexibilizados, o que vem se configurando como um processo político incremental de erosão do pacto constitucional. Contudo, essa resistência moderada e politicamente seletiva das instituições republicanas cobra um alto preço em termos de legitimidade política e no que se refere ao grau de adesão social substantiva ao regime democrático.

No limite, a ausência de efetiva adesão social à democracia e o obscurecimento das forneiras institucionais entre democracia e autoritarismo degradam a natureza do regime e o próprio papel das instituições como guardiãs de uma república democrática. Afinal, as instituições republicanas não devem se restringir apenas a resolver conflitos entre facções de elites que eventualmente assumem a forma de conflitos entre os poderes republicanos. Elas também devem garantir as plenas condições de acesso do demos à polis.

Ressalta-se que esse consenso conservador acerca dos limites da democracia possível e da postura que as instituições da república devem adotar diante de ameaças ao regime democrático não é circunstancial e nem emergiu em decorrência das ameaças contempladas na atual conjuntura crítica. Na verdade, ele apresenta um longo enraizamento histórico e se encontra nos próprios eventos, atores e princípios institucionais que instauraram o regime republicano. Valores políticos elitistas e práticas oligárquicas das lideranças políticas foram ancorados em arranjos institucionais duradouros, orientados para a exclusão social e política de grande parte da população e para propiciar acesso das elites aos recursos estatais. A própria República nasceu com um golpe de Estado e representou um retrocesso eleitoral em relação à antiga monarquia. Com a instauração do regime republicano, em novembro de I889, o regime conseguiu a façanha de reduzir ainda mais o já escasso número de votantes existentes no Império. No ano do primeiro censo demográfico, realizado em 1872, o eleitorado representava em torno de I0\% da população, embora nas primeiras eleições diretas após as restrições da Lei Saraiva aos analfabetos, de I88I, os votantes tenham representado I,25\% da população total. Mas o regime republicano proibiu o voto de menores de 2I anos, mulheres, analfabetos, mendigos, soldados rasos, indígenas e integrantes do clero, o que reduziu os votantes para $2 \%$ da população nas primeiras eleições diretas para presidente, em I894, quando menos de 300 mil eleitores votaram (CARVALHO, 200I; NICOLAU, 2002).

As regras eleitorais instauradas com o advento da República mostram que o sistema republicano brasileiro manteve uma linha de continuidade com a tradição de exclusão popular do processo político e de restrição social para o acesso aos cargos públicos, realidade 
vigente desde os primórdios da colonização, nos séculos XVI e XVII. Diante das limitações operacionais e político-administrativas do precoce Estado português, cargos e funções estatais, privilégios fiscais e concessões especiais de exploração mercantil eram reservados para a elite patrimonialista que operava o Estado colonial (CALDEIRA 2OI7; FAORO, 200I).

Portador dessa origem patrimonial e oligárquica, o regime republicano se cristalizou principalmente como um conjunto de arranjos institucionais orientados para mediar os conflitos entre as elites, com reduzida abertura à participação social. Mas nascendo sob o signo de uma conspiração civil militar e operando sob a ausência de um sólido consenso entre as elites acerca das regras do processo político e eleitoral, as rupturas institucionais no Brasil republicano têm sido uma constante: dos 22 mandatos presidenciais selecionados pelo voto direto desde o advento da República de I889, apenas I 2 foram concluídos em pouco mais de I 28 anos de regime republicano. Se for considerado apenas o período do pós-guerra, de maior complexidade política e socioeconômica, a estatística é dramática: apenas cinco presidentes escolhidos em eleições diretas concluíram o mandato a partir de 1946, incluindo o primeiro mandato de Dilma Rousseff. Sem exceção, as rupturas políticas foram impulsionadas originalmente por conflitos entre facções das elites políticas, grande parte delas provocada por dissensos entre as elites acerca do grau de tolerância diante da possibilidade de que políticas de redistribuição social se tornassem prioritárias na agenda estatal.

Posto o quadro inicial sobre o contexto da crise, o objetivo dos próximos tópicos é discorrer sobre algumas das bases políticas e institucionais da crise da democracia e porque ela vem se tornando vulnerável ao contexto de recente radicalização política impulsionada pelo governo do presidente Bolsonaro. No tópico seguinte, debate-se o papel dos espaços estatais na vigência de mecanismos de seletividade política no âmbito do Estado, mostrando como esses mecanismos de participação seletiva, instaurados desde a década de 1930 por meio do corporativismo estatal, persistiram e foram renovados durante governos recentes. O terceiro tópico trata de como as demandas corporativistas permearam as instituições do sistema de Justiça desde o governo Lula e contribuíram para um processo político de autonomização político-institucional dessas instituições no contexto da democracia brasileira. Por fim, no quarto tópico, são feitas algumas considerações sobre a situação atual da democracia brasileira e estabelecidas algumas ilações acerca das possibilidades futuras de estabilização política em um quadro político radicalizado. 


\section{Espaço estatal como mecanismo de incorporação política seletiva ${ }^{1}$}

No contexto do processo de industrialização e de urbanização deflagrado a partir dos anos 1930, a elite político-administrativa do primeiro período Vargas se antecipou ao problema de redistribuição por meio de um complexo sistema corporativo estatal de integração social. Em um contexto de rápida ampliação político-organizacional do Executivo e de construção de mecanismos de centralização política e administrativa, a Presidência da República se situou como a instância encarregada de coordenar o aparato políticoadministrativo do Estado e mediar as relações do governo com as elites políticas, iniciando a sua trajetória de centralidade no sistema político brasileiro (ARAÚJO FILHO, 2OI6a). Mas isso colocou o Executivo e suas arenas corporativas como o espaço privilegiado de resolução dos problemas de redistribuição social, um problema que iria persistir durante os próximos 90 anos. A república democrática de 1946 não modificou esse padrão, pois o sistema corporativista possibilitava transferir para o Estado as questões mais problemáticas das políticas sociais e do conflito distributivo, liberando o Legislativo da responsabilidade direta de eventuais fracassos das políticas governamentais (SANTOS, I988).

A experiência original do corporativismo estatal consolidou o Executivo como espaço político-institucional de resolução dos problemas de redistribuição, que está na raiz da institucionalização desse modelo em países da América Latina. Brasil, México e Argentina adotaram regimes corporativistas como uma solução político-institucional das elites para coordenar o conflito social derivado do surgimento das massas na política, em meio à incapacidade das oligarquias agrárias de controlar as crises políticas no contexto da modernização econômica (LINZ, I980; STEPAN, I980).

No Brasil, o pluralismo limitado do corporativismo estatal possibilitou ao sistema político resolver problemas de integração política e redistribuição social por meio de estatutos segmentados de cidadania e dos mecanismos de cooptação sindical sob a coordenação do Estado (DINIZ; BOSCHI, I99I; SANTOS, I979; VIANNA, 1976). A experiência corporativista gerou sistemas paraestatais institucionalizados de cooptação política e uma cultura orientada para a valorização da autoridade estatal verticalizada. O modelo corporativista instituiu uma cidadania funcional regulada e formas organizacionais tutelada pelo Estado tutelada pelo Estado, sistema que se antecipou à consolidação de um sistema político representativo com base na competição partidária e reforçou as burocracias estatais como agentes de intermediação e de representação de interesses (COSTA, I99I; NUNES, 1997;

\footnotetext{
${ }^{1}$ Este item contempla parágrafos modificados extraídos de dois artigos de Araújo Filho, a saber: "A crise da democracia brasileira e os limites dos padrões de incorporação política vigentes durante os governos do Partido dos Trabalhadores" (2019) e "Democracia, corporativismo e ruptura institucional: notas sobre os condicionantes políticos da crise e a natureza da democracia no Brasil” (2020).
} 
SOUZA, 1976). Essa complexa engenharia político-institucional de organização social ultrapassou o regime autoritário de Vargas e sobreviveu nas arenas estatais dos regimes políticos posteriores, inclusive durante as tentativas de desmonte do Estado nos anos 1990. Com a ascensão do PT ao poder, os mecanismos corporativistas de integração política foram renovados e utilizados como forma de integração política.

\section{A persistência da seletividade política}

O terceiro pilar estratégico - e o que mais tipificou o perfil político-institucional e administrativo do governo e suas relações com os movimentos sociais organizados - foi o amplo sistema de colegiados participativos estruturado no âmbito interno do Executivo. Ali, foram criados mecanismos funcionais participativos nas políticas e nos programas sociais, com base em grandes conferências nacionais setoriais, colegiados participativos e comissões técnicas, mecanismos de integração que articulavam a burocracia estatal dessas políticas com os movimentos sociais organizados.

O sistema de integração sócio-política estruturado pela coalizão governamental liderada pelo Partido dos Trabalhadores (PT) e pelo então presidente Lula, a partir de 2003 , passou a apresentar um desenho de incorporação política baseada em três pilares estratégicos de clivagens com a sociedade organizada. O primeiro pilar foi orientado para o reforço do sistema de regulação do mercado com base nos arranjos institucionais das agências reguladoras independentes criadas durante os anos 1990, eixo das relações do Estado com os grupos empresariais que detinham concessões estatais de serviços públicos privatizados, como telecomunicações, energia, transportes e mesmo a política de saúde suplementar por meio da Agência Nacional de Saúde Suplementar (ANS). Trata-se de um modelo de regulação com base em negociações diretas entre entes reguladores e regulados, em que a transparência e os princípios objetivos do direito positivo foram substituídos por um processo de negociação informal entre as grandes empresas prestadoras de serviços e as agências reguladoras, espaço em que as tratativas sobre lucros, investimentos e qualidade dos serviços passaram a ocorrer sob um restrito escrutínio público (BOCHI, 2002; NUNES; RIBEIRO; PEIXOTO, 2007).

Os outros dois pilares estratégico adotado pelos governos do PT se cristalizaram na renovação de desenhos organizacionais corporativistas, mas agora ancorados em arranjos institucionais adaptados ao processo de modernização dos mercados de investimentos e ao ampliado sistema de participação estruturado a partir de 2003 no Executivo. No contexto de um capitalismo orientado politicamente(GUIMARÃES, I977), o segundo foi estruturado por meio da ampliação do poder financeiro das centrais sindicais e do sistema sindical corporativista, 
conferindo aos sindicatos das estatais um papel relevante nos colegiados gestores dos fundos de pensão das estatais. ${ }^{2}$ Com isso, o governo soldou uma ampla aliança - embora transitória, como tornou-se evidente após a crise - envolvendo o grande empresariado, as lideranças sindicais e a alta burocracia gestora dos fundos de pensão das estatais.

O processo de interação entre as lideranças sindicais e o grande empresariado incrementou o potencial de cooptação política do sistema, pois deslocou as lideranças sindicais de um ambiente de negociação tradicionalmente circunscrito às áreas de organização do processo de trabalho e de proteção social do trabalhador, para uma agenda de questões mais amplas, vinculadas ao modelo mais abrangente de capitalismo politicamente orientado em curso. Dado o poder financeiro dos fundos de pensão para o ambíguo desenvolvimentismo adotado pelo governo (SINGER, 2OI6), lideranças das centrais sindicais e diretores de fundos de pensão das estatais passaram a se inserir no universo social e político dos executivos empresariais. Essas mudanças no tradicional ambiente sindical contribuíram indiretamente para o distanciamento da direção do PT de sua antiga base social e dos interesses difusos mais abrangentes, ao mesmo tempo que reforçou a inflexão do governo em direção a um capitalismo orientado para as grandes empresas nacionais.

O desenho institucional dessas políticas passou a contemplar mecanismos decisórios de repasses de fundos para a gestão de serviços e equipamentos públicos nas políticas de saúde, educação, assistência social e em programas sociais focalizados. Com esses requisitos administrativos, os movimentos sociais foram impulsionados a se transformarem em organizações com o status de pessoa jurídica, capazes de satisfazerem os requisitos sistêmicos e jurídico-administrativos do Estado racional legal. Trata-se de um fenômeno estrutural de racionalização paraestatal dos movimentos sociais, mas dentro de uma lógica corporativista renovada pelos mecanismos de articulação social desenvolvidos no âmbito do processo de modernização administrativa do Estado (ARAÚJO FILHO, 20I4, 20I6a).

As grandes conferências nacionais eram uma das principais âncoras de mobilização social desse sistema governamental de participação, mas os conselhos participativos instaurados no Executivo foram os mecanismos institucionais efetivos de articulação política entre o governo e os movimentos sociais organizados (SOUZA, 2OI2). Dada a influência operacional do grande número de conselhos que operavam nas arenas do Executivo, era preocupante o perfil político dos conselheiros, mais orientados por valores e interesses específicos do que para o reforço de uma democracia socialmente participativa.

\footnotetext{
${ }^{2}$ Até 2008, apenas sindicatos, federações e confederações sindicais recebiam parcelas da contribuição sindical. Mas em 2008, o então presidente Lula sancionou a lei que autorizou as centrais a partilharem os recursos desse imposto. De acordo com dados de $O$ Estado de São Paulo, de 22 de junho de 2015, de 2008 a junho de 2015 as centrais sindicais receberem um total de 1 bilhão de reais.
} 
Pesquisa realizada com conselheiros de 2I conselhos e três comissões indicou que apenas $39 \%$ afirmaram que defendiam interesses de toda a coletividade e cerca de $80 \%$ declararam que representavam uma base organizacional ou setorial específica (IPEA, 20I3). Em termos de assimetria informacional diante das burocracias setoriais, 6I,5\% dos conselheiros admitiram ter uma compreensão parcial dos assuntos tratados e 5I,8\%, uma compreensão restrita da linguagem utilizada, problema já identificado por Fonseca (2012) em sua pesquisa sobre o Conselho Nacional do Meio Ambiente (CONAMA). Mas apesar dessas limitações em um ambiente estatal de alta complexidade técnica, organizacional e administrativa, $4 \mathrm{I} \%$ declararam que atuavam em mais de um conselho, revelando que havia uma convergência entre os interesses das burocracias setoriais que coordenavam os colegiados e a alta rotatividade setorial dos representantes, com a profissionalização e o monopólio da representação por um grupo restrito de conselheiros, fenômeno que era bastante visível em alguns dos mais importantes colegiados setoriais, como demonstrado em Araújo Filho (2016a). E o mais preocupante, apenas I3\% consideraram o fortalecimento da democracia como um dos aspectos relevantes dos conselhos (IPEA, 2OI3).

Um fenômeno político crucial para o processo político posterior emergiu quando essa lógica de seletividade política também se projetou externamente para instituições do sistema de Justiça. Logo no início do seu mandato, em 2003, o presidente Lula chancelou administrativamente a demanda corporativa do Ministério Público Federal (MPF), definindo que a escolha do procurador-geral da república - de prerrogativa constitucional do presidente da república -, deveria ser realizada por meio de uma lista tríplice resultante de um processo eleitoral interno, no qual só os procuradores do MPF são eleitores. Essa norma de natureza corporativista reforçou o poder político da alta burocracia do MPF, uma instituição que já tem uma excessiva autonomia política e constitucional diante dos demais poderes da República. Com isso, o processo de politização do Judiciário e o reforçado poder político-institucional do MPF se situaram como fatores cruciais para o processo de impeachment da presidenta Dilma Rousseff, em 20I6. Com a presidência política e institucionalmente fragilizada, as altas burocracias do Judiciário e do MPF, integrantes da elite social do país e identificadas com valores políticos conservadores, assumiram a agenda de grupos político-partidários da direita a partir de 20I4. E por meio de uma aliança tácita com grandes empresas da mídia do país, Judiciário e MPF precipitaram um processo de cerco judicial ao governo, resultando na queda de Rousseff e na posterior condenação e prisão do ex-presidente Lula.

Sem desconsiderar os fatores relativos à crise econômica do período e os erros específicos do estilo presidencial de Rousseff, cabe ressaltar que a convergência entre a disseminação de padrões formais e informais de corporativismo estatal em áreas importantes do Executivo e do 
sistema de Justiça, e também nas relações estabelecidas entre Estado e segmentos da sociedade organizada, foi uma das causas primárias da fragilização do governo e do próprio pacto constitucional de I988, crise esta que desaguou na ruptura institucional de 2016 e na profunda erosão dos princípios republicanos.

\section{Processo de judicialização e autoritarismo na democracia brasileira}

Sob o prisma de uma concepção elitista de democracia e república, pode-se admitir que o STF tem funcionado como um dos principais diques de contenção da escalada golpista deflagrada pelo presidente Bolsonaro. A Corte se defrontou com frequentes ataques de seguidores mais fanáticos do bolsonarismo e de integrantes de seus círculos palacianos, e reagiu por meio do Inquérito das Fake News, uma estratégia de setores da extrema direita que se consagrou desde as eleições de 20I8, com a leniência do próprio STF e do Tribunal Superior Eleitoral (TSE). No entanto, o STF só reagiu quando os ataques passaram a se orientar diretamente para seus membros. Desde então, o STF tem imposto limites aos impulsos golpistas de Bolsonaro e de seus seguidores e sagrou-se, aos olhos da mídia e dos mais desatentos às dinâmicas históricas mais longas, como oficialmente vitorioso no embate com o presidente no 07 de setembro de $202 \mathrm{I}$.

Na perspectiva deste artigo, o o7 de setembro foi o corolário de uma longa trajetória de cumplicidade tácita do STF com o projeto de retomada do tradicional leito elitista do sistema político brasileiro. Esse projeto se iniciou com as formas de julgamento do "mensalão", e se desdobrou na participação da Corte na legitimação constitucional do ambíguo impeachment de Dilma Rousseff e na postura leniente diante das transgressões da campanha presidencial e aos primeiros dezoito meses do governo Bolsonaro.

O mandato de Bolsonaro tem se caracterizado pela permanente mobilização e radicalização política de massas que clamam por intervenção militar e ruptura institucional da democracia e por sucessivas e caóticas trocas de quadros ministeriais, enquanto delega a seus ministros e auxiliares a administração rotineira de governo, mas sem que tenha formulado ou implementado qualquer política de proteção social para o país (ARAÚJO FILHO; AZEVEDO ARAÚJO, 2020). Contrariamente, o presidente se dedicou a desenvolver uma campanha sistemática contra os procedimentos de proteção indicados pelas autoridades do sistema de saúde da ONU no contexto da grave pandemia que assolou o país. Apesar desse comportamento, que inclui recorrentes ameaças à ordem constitucional e formação de redes sociais dedicadas a atacar adversários políticos e membros das instituições 
da República, durante a conturbada campanha presidencial e nos primeiros dezoitos meses de governo, o STF se manteve olimpicamente "neutro" diante da incremental erosão do clima político do país.

Nesse sentido, a postura recente da Corte é fruto de uma reação aos excessos generalizados da Operação Lava Jato, mas também ao espaço político que esta vinha adquirindo sobre o próprio STF. ${ }^{3}$ Antes dessa tardia reação, o protagonismo assumido pelo sistema de Justiça nos anos recentes contribuiu significativamente para o atual cenário de instabilidade política. O Poder Judiciário e outras instituições do sistema de justiça desempenharam um papel determinante no impeachment de Dilma Rousseff e, ao contribuírem para uma profunda desorganização político-institucional do sistema político, abriram espaço para a eleição de um candidato presidencial sem compromissos com as tradicionais regras do sistema político e ou com a estabilidade da democracia. Tais acontecimentos são frutos de um processo mais amplo de judicialização da política e de politização da justiça que vem ganhando corpo nas últimas décadas. As fronteiras entres os poderes republicanos foram obscurecidas, um forte clima de antipolítica foi disseminado na população e o combate à corrupção foi alçado à condição de uma cruzada capaz de sobrepujar todos os demais valores republicanos.

A Operação Lava Jato foi o ápice desse processo. Em nome do combate à corrupção, violou direitos e princípios constitucionais básicos, e instilou, em boa parte da população, um forte sentimento de antipolítica que levou à vitória do bolsonarismo, em 20I8. Seus operadores ancoraram sua atuação em um repertório cultural autoritário que transbordou os limites de tal operação e serviu, inclusive, para minar alguns dos princípios que teoricamente a baseavam, como a transparência e a submissão de todos à Lei (SÁ E SILVA, 2020). Com o beneplácito da grande mídia, que desde o Mensalão passou a disseminar na opinião pública a noção de que a corrupção era o principal problema do Brasil, a Lava Jato produziu uma profunda desorganização do sistema político brasileiro, desfazendo seu frágil equilíbrio.

A prisão de Lula - um dos principais resultados da transferência de poder da classe política para a elite do sistema de Justiça - retirou das eleições o único candidato que poderia ter contido Bolsonaro em 20I8. E se é verdade que em 2020 o lavajatismo e o bolsonarismo antes unidos pelo eixo do antipetismo - se descolaram por ocasião da saída de Sérgio Moro do Ministério da Justiça, é inegável que a união de ambos gerou a configuração política

\footnotetext{
${ }^{3}$ As conversas dos procuradores expostas pela Vaza Jato indicam que os operadores investigavam os próprios ministros do STF. Disponível em: <https://brasil.elpais.com/brasil/2019/08/05/politica/1565040839_880977.html>. Acesso em: 06 ago. 2019; $<$ https://www.cnnbrasil.com.br/politica/novas-mensagens-mostram-intencao-da-lava-jato-de-investigar-ministros-do-stj/>. Acesso em: 04 fev. 2021.
} 
autoritária atualmente vigente. Também é dispensável aqui detalhar o papel determinante da grande mídia e do apoio quase unânime da elite socioeconômica do país a esse processo de fragilização da democracia, visto que não se mostraram preocupadas com os efeitos deletérios da operação sobre a economia nacional, em especial sobre os setores de óleo, gás e construção civil, os quais são importantes para a incipiente expansão do capitalismo brasileiro para a América Latina e a África.

Destaca-se que a atuação dos operadores da Lava Jato - fenômeno que poderia ser caracterizado como uma cruzada religiosa se hoje não fossem públicos os desvios éticos e jurídicos cometidos pela denominada República de Curitiba - se inseria originalmente em um ambiente político e jurídico que contou com sustentação no STF, que inclusive passou a encampar teses jurídicas questionáveis em nome do combate à corrupção, como a Teoria do Domínio do Fato, desmembrada de seus cânones originais para servir como instrumento maleável de julgamento no processo do Mensalão. E, se em 202I, ela definiu a I3 ${ }^{\text {a }}$ Vara de Curitiba como incompetente para julgar o processo contra Lula e situou o juiz Sergio Moro como suspeito, abrindo possibilidades para a candidatura de Luís Inácio Lula da Silva em 2022, no início da operação várias decisões do STF reforçaram seu arbitrário poder político, a exemplo da decisão pela prisão em segunda instância. O próprio ministro Gilmar Mendes, que chegou a afirmar no seu voto sobre a incompetência da I3- Vara que a "Operação Lava Jato foi o maior escândalo judicial da história", ${ }^{4}$ era um entusiasta quando o PT estava no controle do governo. Basta recordar sua decisão de anular a nomeação de Lula para a Casa Civil, em março de 20I6, na esteira do vazamento de escutas ilegais por Sergio Moro, eliminando qualquer possibilidade de sobrevivência do governo Dilma Rousseff.

Observa-se que o reconhecimento da contribuição do Judiciário e do sistema de Justiça como um todo para a atual crise pode abrir espaço para uma interpretação superficial desse processo: a de que a hipertrofia política do sistema de justiça se deu apesar ou até mesmo contrariamente à agenda dos governos petistas. Contudo, o que ocorreu foi justamente o oposto: os governos petistas não limitaram sua agenda corporativista às arenas participativas do Executivo, visto que ela também se estendeu para o sistema de Justiça, impulsionando sua hipertrofia política e seu voluntarismo punitivo contra grupos políticopartidários que destoavam da ideologia política dos membros da operação. Consolidados pela autonomia propiciada pelos governos do PT e ancorados numa forte aliança com a grande mídia e com setores da elite socioeconômica na agenda anticorrupção, os atores do

\footnotetext{
${ }^{4}$ Disponível em: <https://www.poder360.com.br/justica/gilmar-mendes-diz-que-lava-jato-e-o-maior-escandalo-judicial-dahistoria/>; <https://www1.folha.uol.com.br/poder/2021/03/>. Acesso em: 09 mar. 2021.
} 
sistema de Justiça foram fortalecidos também por políticas corporativistas e pouco republicanas nesse período, gerando uma situação em que a criatura devorou seu criador.

É importante observar que numa perspectiva histórica mais ampla, o fortalecimento das instituições de controle e a criação de uma extensa rede de accountability durante os governos petistas foram a continuidade de tendências estruturais anteriores. Vianna (1999) já havia identificado como o processo de judicialização passou a se situar como uma das características da dinâmica política brasileira após a Constituição de I988. E em uma ampla abordagem sobre os processos de autonomização dos subsistemas técnicos e dos códigos do direito nas democracias ocidentais, Habermas (1997) já havia indicado como esse processo ameaça a sobrevivência da democracia, reforça o mundo dos subsistemas técnicos e provoca erosão de um pacto republicano ampliado. Contudo, no exemplo do Brasil, foi no governo Lula que o processo de autonomização dessas instituições adquiriu massa crítica (PRAÇA; TAYLOR, 20I4).

O ator que incialmente capitaneou esse processo foi Marcio Thomaz Bastos, conhecido por sua capacidade de articulação política no âmbito desses sistemas. As reformas operadas pelo Ministério da Justiça sob o comando de Bastos não se restringiram ao Judiciário. Elas atingiram as demais instituições da rede de accountability e catalisaram reformas que perduraram após sua gestão, impulsionando o processo de autonomização das instituições do sistema de Justiça. A seguir serão analisadas algumas das transformações operadas durante os governos petistas em duas das instituições do sistema de Justiça, a Polícia Federal (PF) e o MPF, além da criação da Estratégia Nacional de Combate à Corrupção e Lavagem de Dinheiro (ENCCLA), importante inciativa de articulação político-institucional em rede que nasceu em 2003 e influenciou significativamente as políticas de combate à corrupção, fornecendo suporte a alianças entre organizações e atores do sistema de Justiça.

\section{Polícia Federal e Ministério Público Federal}

O número de operações desenvolvidas pela PF antes de 2003 era relativamente pequeno. Foram 48 operações durante o período FHC, e 3.512 durante os governos petistas. Mas, além do aumento da quantidade de operações, a PF passou a focar mais em investigações de crimes de colarinho branco, tipo de foco que, já em 2013, suplantou as investigações sobre contrabando e tráfico de drogas. Nessa inflexão, a PF contou com parcerias com a Controladoria-Geral da União (CGU) e o Tribunal de Contas da União (TCU), típicas instituições de controle administrativo e fiscalização financeira, cujos relatórios técnicos e auditorias são usados para fortalecer provas nas investigações. 
Desde os anos 2000 que a base operacional e administrativa da PF vinha sendo fortificada. O quantitativo de profissionais da instituição se multiplicou com a realização de diversos concursos públicos para o ingresso na carreira, que atingiu um efetivo total de cerca de 12 mil funcionários em 2015. Nesse período, a instituição aprimorou suas técnicas de investigação, com a incorporação de novas tecnologias e com a modernização da doutrina operacional e de investigação, adotando um modelo mais ativo de obtenção de provas, com enfoque nas lideranças das organizações criminosas (SANTOS, 20I7). Além da própria PF, uma das principais instituições a se beneficiarem desse processo de fortalecimento institucional e de modernização tecnológica foi o MPF, que durante a Lava Jato passou a mobilizar a PF como seu braço policial para acelerar operações, emergindo uma aliança tácita entre as duas instituições que se tornou uma das características do voluntarismo punitivo e circense do período.

Quanto ao MPF, sua trajetória não se restringiu às mudanças na política operacional e organizacional do período recente, pois apresenta uma raiz ancorada na Constituição de 1988. Esta atribuiu ao MPF elevado grau de autonomia e independência funcional, contrastando com sua história anterior de relativa subordinação aos demais poderes da República. Situados em um contexto de reação ao autoritarismo do regime militar e influenciados por um forte lobby da Confederação Nacional do Ministério Público (CONAMP), os constituintes optaram por retirá-lo do controle do Ministério da Justiça e conferir a ele um largo leque de atribuições (KERCHE, 1999). Sua autonomia se situou como dupla, exercida tanto diante dos demais poderes quanto internamente, visto que os instrumentos hierárquicos dentro da sua estrutura político-organizacional são frágeis e os procuradores têm grande proteção diante de seus pares e diante do procurador-geral (KERCHE, 2OI4).

A autonomia externa se tornou ainda mais forte com a prática, adotada pelos governantes do PT, de indicar o primeiro colocado da lista tríplice enviada pelo órgão. $\mathrm{O}$ presidente Lula rompeu com a prática do governo anterior de nomear um procurador-geral leal ao governo. Durante o governo FHC, o procurador Geraldo Brindeiro foi reconduzido ao cargo três vezes, inclusive em 200I, quando a Associação Nacional dos Procuradores da República (ANPR) passou a promover a formação de listas tríplices bienais e Brindeiro não constava nela.

Criou-se, assim, uma espécie de regra informal de natureza corporativa, vigente em todos os governos petistas, que derivava diretamente de uma concepção corporativista e sindicalista de Estado, sem considerá-lo como uma dimensão pública que não deveria ser objeto de captura por parte de burocracias funcionais. Essa nova "tradição", inaugurada pelo governo Lula, foi rompida parcialmente no governo de Michel Temer - que nomeou a 
segunda colocada da lista, Raquel Dodge - e por completo no governo de Jair Bolsonaro, que nomeou Augusto Aras, que estava fora da lista tríplice.

Ancorado sobre uma base constitucional que lhe fornecia ampla autonomia no contexto da República e na própria cumplicidade do Poder Executivo para com suas reivindicações corporativas, a partir de 2003, o MPF também se fortaleceu com a prática de conduzir investigações relativas aos crimes de colarinho branco. Essa prerrogativa há muitos anos é um ponto de tensão entre o MPF e a própria $\mathrm{PF}$, posto que na Constituição de 1988 o inquérito criminal não consta no rol de responsabilidade do MPF, cabendo-lhe apenas requisitar diligências e instaurar inquérito policial. ${ }^{5}$ Entretanto, em 2015, o STF avalizou essa prática e decidiu - com repercussão geral - que o MPF detém poder de investigar por iniciativa própria. Com base nessa prerrogativa, o órgão criou, sem previsão legal, grupos de procuradores especializados em diferentes assuntos, como combate à corrupção, combate ao tráfico de drogas, entre outros, o que favoreceu o surgimento das "forças-tarefa" (MARONA; KERCHE, 202I), efetivamente redes grupais que comungavam concepções comuns acerca de critérios de justiça, princípios processuais e seleção de grupos de corruptos a serem investigados.

Esse processo de autonomização político-institucional e de ampliação das prerrogativas do MPF têm sido objeto de vários estudos da Ciência Política, muitos deles críticos a esse processo. Avritzer e Marona (2017) afirmam que a trajetória recente do MPF e as inovações institucionais ocorridas no sistema judicial apontam para uma espécie de pretorianismo sobre as instituições políticas, um MPF não responsivo, que pode trazer riscos para a ordem política democrática (KERCHE, 20I8). Ainda na década de 1990, Rogério Arantes identificou uma ideologia do "voluntarismo político" na instituição, que "incorpora a crença de que a instituição tem um papel protetivo em uma sociedade que é incapaz de se defender em um contexto em que os poderes políticos representativos estão corrompidos ou incapazes de cumprir seus deveres" ${ }^{6}$ (ARANTES, 2005, p. 250, tradução livre).

\footnotetext{
${ }^{5}$ CF. Art. 129: "São funções institucionais do Ministério Público: [...] VIII - requisitar diligências investigatórias e a instauração de inquérito policial, indicados os fundamentos jurídicos de suas manifestações processuais".

CF. Art. 144: "A segurança pública, dever do Estado, direito e responsabilidade de todos, é exercida para a preservação da ordem pública e da incolumidade das pessoas e do patrimônio, através dos seguintes órgãos: I - polícia federal; II - polícia rodoviária federal; III- polícia ferroviária federal; IV - polícias civis; V- polícias militares e corpos de bombeiros militares. VI - polícias penais federal, estaduais e distrital. [...] § 40: Às polícias civis, dirigidas por delegados de polícia de carreira, incumbem, ressalvada a competência da União [Polícia Federal], as funções de polícia judiciária e a apuração de infrações penais, exceto as militares."

Disponível em: <http://www.planalto.gov.br/ccivil_03/constituicao/constituicao.htm>. Acesso em: 21 nov. 2021.

6 "With respect to the members of the MP, qualitative research indicates that their ideologies can be classified as one of 'political voluntarism', which embodies a belief in the institution's protective role in a society that is incapable of defending itself and in the context of a representative political power that is corrupt or incapable of fulfilling its duties."
} 


\section{Estratégia Nacional de Combate à Corrupção e Lavagem de Dinheiro}

A Estratégia Nacional de Combate à Corrupção e Lavagem de Dinheiro (ENCCLA) transformou a burocracia estatal anticorrupção em um grande corpo, dotado de relativa coesão política e com estratégias e interesses comuns, cujas partes passaram a se comunicar de modo relativamente livre e, em alguns momentos, a se mover em uníssono. A rede foi criada em 2003, quando Marcio Thomaz Bastos era ministro da justiça, e teve como inspiração uma inciativa anterior de um grupo de juízes liderados pelo ministro do STJ Gilson Dipp, de criar varas especializadas para o combate a crimes financeiros (LAFORGE, 2017). O modelo inicial do que viria ser a ENCCLA foi estabelecido pelo então advogado da união Antenor Madruga, diretor do Departamento de Recuperação de Ativos e Cooperação Jurídica Internacional (DRCI), entre 2003 e 2006.

Para a plena compreensão das implicações políticas resultantes da criação dessa rede, deve ser observado que a ENCCLA não é, de fato, um órgão de Estado. Ela não tem autonomia institucional ou existência administrativa, funcionando efetivamente como uma rede informal. As funções administrativas da ENCCLA são de responsabilidade do DRCI, que aloca recursos orçamentários para suas atividades (FLORÊNCIO FILHO; ZANON, 2OI8). Seus membros se encontram em plenária uma vez por ano, quando aprovam as ações correntes e as ações do ano seguinte, sendo esse evento anual o mais importante da rede. Grupos de Trabalho, organizados em função da temática e constituídos informalmente, são responsáveis por concretizar as ações definidas na plenária. Há, também, um Gabinete de Gestão Integrada, composto por algumas entidades governamentais que se reúnem a cada três meses para realizar o acompanhamento da execução das ações.

O número de participantes na ENCCLA aumentou ao longo dos anos. Passaram a participar da rede dezenas de órgãos estratégicos de fiscalização, controle e informações dos três Poderes da República, entre eles a Agência Brasileira de Inteligência (ABIN), a Controladoria-Geral da União (CGU), o Conselho de Controle de Atividades Financeiras (COAF), o Conselho Nacional de Justiça (CNJ), o Tribunal de Contas da União (TCU), além dos Ministérios Públicos dos estados e o MPF. Conta ainda com a participação de diversas associações corporativas, como a Associação dos Juízes Federais (AJUFE), a Associação Nacional dos Procuradores da República (ANPR), a Associação Nacional dos Delegados de Polícia Federal (ADPF), entre outras, que encontram na rede uma oportunidade ímpar de exercer influência sobre o aparelho de Estado e as políticas públicas de combate à corrupção e lavagem de dinheiro. 
A ENCCLA possibilitou a formação de uma rede de articulação interinstitucional de natureza relativamente informal, não hierárquica e não burocrática, tornando-se capaz de coordenar esforços de modo dinâmico. Segundo Antenor Madruga, diretor do DRCI, entre 2003 e 2006:

\begin{abstract}
A informalidade na constituição do grupo que definiria a estratégia nacional de combate à lavagem de dinheiro foi essencial para reunir numa mesma mesa órgãos e autoridades que tinham poder de fato nesse tema, mas representavam hierarquias distintas. Se seguíssemos o modelo de cooperação administrativa tradicional, com grupos de trabalho formalmente constituídos, publicados no Diário Oficial, prazos rígidos e zelos hierárquicos, provavelmente a ENCCLA teria se perdido nos meandros da burocracia e não estaria próxima a completar uma década.
\end{abstract} (MADRUGA, 20I2). ${ }^{7}$

Os resultados efetivos da ENCCLA são muitos. A meta 25/2004 levou à criação do Programa Nacional de Capacitação e Treinamento para o Combate à Corrupção e à Lavagem de Dinheiro (PNLD), que capacitou milhares de agentes públicos no combate a esses crimes. Valendo-se da experiência adquirida com o PNLD, o DRCI desenvolveu o Programa Nacional de Difusão de Cooperação Jurídica Internacional (GROTIUS BRASIL), que objetiva promover a capacitação de agentes em cooperação internacional e fomentar o ensino, a pesquisa e a extensão acadêmica nessa área. A rede também estimulou a criação de delegacias especializadas em crimes financeiros e de sistemas e bancos de dados importantes, como o Cadastro de Clientes do Sistema Financeiro, o Sistema de Investigação de Movimentações Bancárias, o Sistema de Fornecimento de Informações ao Poder Judiciário e o Sistema Nacional de Bens Apreendidos. ${ }^{8}$

Os resultados da rede produziram uma boa imagem no exterior e em organizações internacionais. O Grupo de Ação Financeira Internacional (GAFI), em seu relatório de avaliação mútua do Brasil de $2010,{ }^{9}$ faz várias referências a ela e a identifica como um importante fator de progresso:

Outro fator importante que tem contribuído para o progresso do Brasil é o mecanismo ENCCLA, por meio do qual o Brasil desenvolveu uma estratégia de "Combate ao Financiamento do Terrorismo"/"Antilavagem de Dinheiro"

\footnotetext{
${ }^{7}$ Disponivel em:<https://www.conjur.com.br/2012-dez-13/cooperacao-internacional-efetividade-lei-lavagem-mostra-exito-encla>. Acesso em: 26 jun. 2021.

${ }^{8}$ Principais resultados disponíveis em: <http://enccla.camara.leg.br/resultados>. Acesso em: 26 jun. 2021.

${ }^{9}$ Os relatórios do GAFI avaliam os mecanismos de controle e prevenção à lavagem de dinheiro e ao financiamento ao terrorismo dos países membros, e prescrevem soluções para as deficiências identificadas.
} 
coerente, fixou metas anuais e revisou sistematicamente seu avanço na implementação de medidas Antilavagem de Dinheiro e de Combate ao Financiamento do Terrorismo. ${ }^{10}$

Essa recepção política não surpreende, visto que a ENCCLA foi um vetor de incorporação de prescrições internacionais relativas ao combate à corrupção e à lavagem de dinheiro, e os objetivos da rede foram, em grande medida, conformados pelas convenções internacionais que tratam dessas matérias (LAFORGE, 20I7). Não é uma simples coincidência que esses princípios convergiam também com as estratégias de combate à corrupção desenvolvidas pelo Departamento de Justiça dos Estados Unidos para a América Latina, no governo de Obama, que resultaram no fortalecimento do Judiciário em países da América Latina e geraram situações de desestabilização política no Peru, no Paraguai, no Equador e no próprio Brasil por meio da Lava Jato, países que tiveram seus governos desestabilizados por estratégias de combate à corrupção. Convém salientar, inclusive, que foram firmados acordos entre o MPF e o Departamento de Justiça norte-americano; acordos citados pela imprensa, mas não publicizados, que contornaram inclusive o próprio Ministério da Justiça e o Itamaraty durante o segundo governo de Dilma Rousseff e o governo de Michel Temer.

Uma das estratégias de Antenor Madruga para fortalecer a adesão à rede e atender às prescrições internacionais foi convidar juízes, procuradores e policiais federais a participarem da delegação brasileira para conferências de implementação da Convenção da Nações Unidas contra o Crime Organizado Transnacional (Convenção de Palermo) e, posteriormente, para outros fóruns internacionais. $\mathrm{Na}$ medida em que os membros da ENCCLA passaram a participar de eventos e seminários internacionais, à pressão dos pares brasileiros foi se somando a pressão de pares estrangeiros, envolvendo um processo de construção hegemônica de determinadas narrativas acerca do problema da corrupção e do papel a ser exercido pelas autoridades do sistema de Justiça.

Isso fez com que a ENCCLA, para além dos resultados já apontados, desempenhasse um importante papel na elaboração e na tramitação de projetos de leis relativos à lavagem e à corrupção, muitos dos quais apoiados em normas internacionais. As inciativas legislativas chanceladas pela rede costumavam receber amplo apoio, inclusive de parlamentares da oposição. A coesão política da rede e sua forte identidade corporativa tratando de um tema percebido socialmente como de base moral, geraram resultados surpreendentes: mesmo que a iniciativa viesse do Executivo ou de um parlamentar governista, ela não era identificada

\footnotetext{
10 "Another important factor contributing to Brazil's progress has been the ENCCLA mechanism through which Brazil has developed a coherent "Anti-Money Laundering"/“Combating the Financing of Terrorism" strategy, set annual goals and systematically reviewed its progress to enhance implementation of AML/CFT measures", trecho do documento da Financial Action Task Force, "Mutual Evaluation Report of Brazil", de 2010.
} 
com os interesses do governo, mas com esforços de um corpo de especialistas empenhados em combater a corrupção e a lavagem de dinheiro. Ou seja, apesar da relevância política dos temas, com potencial de atingir a própria classe política, esses projetos não eram percebidos como passíveis de problematização política por grupos partidários. Afinal, eles se apresentavam como questões éticas de interesse de toda a sociedade, acima das facções e dos interesses político-partidários, justamente o que estava sendo objeto de combate dessas iniciativas em um contexto de forte criminalização da política.

Entre as muitas leis que contaram com a contribuição da ENCCLA, destacam-se a Lei no I2.683/2012 (que modificou a Lei de Lavagem de Dinheiro), a Lei n- 12.846/2013 (Lei Anticorrupção) e a Lei no I2.850/20I3 (Lei de Organizações Criminosas). Essas leis "colocaram à disposição dos operadores do sistema de justiça criminal diversos instrumentos convergentes com a busca de efetividade da punição da corrupção envolvendo grandes empresários e atores políticos de médio e alto escalão" (RODRIGUES, 2019, p. 72-73). Todas elas foram aprovadas durante o primeiro governo de Dilma, indicando que o governo estava desatento às futuras implicações políticas da nova legislação em termos de criminalização da classe política no contexto do lavajatismo, e menos atento ainda ao amplo processo de articulação política e corporativa que transcorria no âmbito das instituições dos sistemas de justiça e de fiscalização estatal. Nesse sentido, se algo pode ser deduzido desse processo acerca do estilo de liderança presidencial da então presidenta Dilma Rousseff, é que sua relativa inexperiência político-partidária e sua baixa disposição para o exercício da política de bastidores foram alguns dos fatores causadores de sua queda.

\section{A natureza da crise e as perspectivas para a democracia no Brasil}

O processo descrito nos itens anteriores indica que a partir do Mensalão houve um deslocamento da autoridade moral do político para o jurídico (FONTAINHA; EVELYN, 2OI9), e o combate à corrupção foi elevado ao status de principal valor simbólico e moral da democracia no Brasil. Essa inflexão situou o Judiciário e o MPF como instituições que demarcaram o espaço de atuação da classe política e criaram profundos desequilíbrios político-institucionais nos anos recentes. Dentre eles, uma profunda erosão na legitimidade do sistema representativo, a debilidade crescente dos princípios políticos orientadores da democracia e um processo de deslocamento da classe política em favor de burocracias não eleitas. O combate à corrupção envolveu a ação voluntarista de numerosos agentes do sistema de Justiça, que incrementaram as incertezas políticas e afetaram significativamente o equilíbrio de poder no âmbito do sistema político. A configuração político-institucional do sistema tornou-se caótica e o processo de combate à corrupção não resultou em um sistema político mais responsivo ou 
transparente. Ocorreu justamente o oposto. Emergiram múltiplas estratégias fragmentadas e conflitantes por parte de atores políticos e de coalizões de defesa de interesses e o sistema não incrementou sua transparência. A cada nova investida jacobina do sistema judicial o sistema político se desorganizava e marginalizava tradicionais lideranças político-partidárias, abrindo espaço para atores não responsivos e aventureiros políticos.

Essa foi a configuração do gradual processo de surgimento e enraizamento institucional de um autoritarismo sistêmico em camadas mais subterrâneas do aparato estatal e particularmente dentro do sistema de Justiça do país. Nesse contexto, a Operação Lava Jato, impulsionada por uma mídia que mobilizou o ressentimento social contra a classe política e alavancou a difusão de valores antidemocráticos, foi uma das principais responsáveis pelo atual estado de radicalização e intolerância social. Atualmente, a sociedade está mais fragmentada e os padrões de sociabilidade têm sido afetados pelo clima de ódio generalizado que a abordagem midiática e circense estimulou durante os anos sombrios do lavajatismo desenfreado.

Essas mudanças no funcionamento do sistema político e no equilíbrio da república geraram uma situação de incerteza política, uma redução no escopo dos direitos, um obscurecimento do papel das instituições e o surgimento de poderes discricionários. $\mathrm{O}$ voluntarismo e a discricionariedade que orientaram as ações do sistema judicial, de 2015 a 2020, transformaram a natureza do Estado brasileiro e abriram espaço para o controle de forças autoritárias e de natureza policial no sistema de Justiça. Com isso, o já escasso republicanismo presente entre as elites políticas brasileiras foi uma das maiores vítimas. Nesse quadro geral, a ruptura institucional de 2016 resultou da convergência entre uma grave crise econômica, um governo com uma fraca base parlamentar, um processo estrutural de judicialização e de criminalização da classe política e tendências incrementais de autonomização do sistema de justiça, se desdobrando na mais grave crise da democracia brasileira desde o advento da Nova República. Mas se os membros da coalizão partidária de centro-direita que derrubaram Dilma Rousseff da presidência tinham objetivos iniciais claros, não conseguiram deter o controle posterior de todos os mecanismos políticoinstitucionais que foram mobilizados para a derrubada do governo.

De maneira distinta das condições econômicas específicas no contexto da Guerra Fria, que possibilitaram aos líderes do golpe de 1964 transformar elementos de uma crise de governo em uma crise de regime e mobilizar amplos segmentos sociais em favor de um regime autoritário, mas não fascista, as tendências autoritárias atuais demonstram tendências fascistas que perpassam o sistema político, as instituições e o processo políticopartidário. Trata-se, na verdade, de uma profunda e múltipla crise: dos próprios ideais democráticos, da tradicional imagem cultural do país e também uma crise dos padrões de sociabilidade que alicerçaram as relações entre classes e grupos sociais no Brasil. 
O potencial de violência social e política incorporada nas práticas e nos valores do bolsonarismo indicam que o processo político mudou de natureza. Mais que isso, aos mais atentos em relação aos conteúdos sociais substantivos dos regimes políticos e aos seus princípios ético-políticos - e não apenas às regras de competição eleitoral e de seleção de elites dirigentes -, não passa despercebido que o regime político instaurado pelo pacto constitucional de 1988 pode ter chegado ao fim, sem indícios claros sobre qual tipo de regime emergirá com as incertas eleições de 2022 e a posse de um novo governo. Na raiz dessas mudanças, estiveram renovadas formas de corporativismo estatal que privilegiavam determinados segmentos dos movimentos sociais organizados, burocracias funcionais e segmentos do empresariado e excluíram parte significativa dos interesses difusos.

A incerteza gerada pela polarização política recente e por movimentos de tendências fascistas que surgiram nos últimos anos aponta para um quadro político incerto para o futuro da democracia. Considerando a continuidade de características da atual conjuntura, que envolvem radicalização da extrema direita, regressão dos valores políticos do patronato rural e consolidação do perfil político de um Judiciário integrante de uma elite social conservadora, as eleições de 2022 tendem a transcorrer em um tenso clima de polarização política. E um processo eleitoral radicalizado tende a se submeter à arbitragem do Judiciário e das Forças Armadas, estamentos não responsivos ao jogo democrático e que podem arbitrar a permanência do futuro governo sob um potencial contexto de recessão econômica e de crise política.

Por fim, convém salientar que a forte aderência do regime democrático a situações de apoio ou rejeição aos governos em curso, em um país socialmente desigual e onde historicamente os governos sempre exerceram um papel importante no bem-estar social e no desenvolvimento econômico, carrega sempre o risco de que a estabilidade da democracia passe a depender do apoio social ao governo. Nesse sentido, a forte imbricação entre estabilidade do regime político e apoio governamental, continua a situar a democracia brasileira como dependente das circunstâncias políticas e da eficiência política e administrativa dos governos em curso.

\section{Referências}

ARANTES, R. B. Constitucionalism, the expansion of justice, and the judicialization of politics in Brazil. In: SIEDER, R. et al. (Eds). The judicialization of politics in Latin America. New York: Palgrave, 2005. 
ARAÚJO FILHO, V.F. de. A crise da democracia brasileira e os limites dos padrões de incorporação política vigentes durante os governos do Partido dos Trabalhadores. In: ROMANO, S. M.; PARRA, I. D. (Orgs.). América Latina, dilemas e desafio. Reflexões sobre la deriva de los gobiernos progresistas. Cádiz-Espanha: Editorial UCA, Universidad de Cádiz, 2019.

ARAÚJO FILHO, V. F. de. A racionalização paraestatal dos movimentos sociais e as manifestações de protesto no Brasil: reflexões sobre as rupturas sociais e a crise de legitimação na democracia brasileira. In: CONGRESSO PORTUGUÊS DE SOCIOLOGIA, 8., 2014 , Évora. Anais... Évora: jun. 2014.

ARAÚJO FILHO, V. F. de. Democracia, corporativismo e ruptura institucional: notas sobre os condicionantes políticos da crise e a natureza da democracia no Brasil. In: GONZÁLEZ, M. V. E.; IAMAMOTO, S.; CRUZ, D. U. (Orgs.). Democracia na América Latina: descolonização, territórios e horizontes. Buenos Aires: CLACSO, 2020.

ARAÚJO FILHO, V. F. de. Presidentes fortes e presidência fraca. A expansão do poder executivo e a organização da Presidência da República no Brasil (I930-I989). Curitiba: Appris, 20I6a.

ARAÚJO FILHO, V. F. de. Seletividade corporativa e institucionalização clientelista no modelo de participação social do poder executivo brasileiro. In: CONGRESSO DO CONSELHO EUROPEU DE INVESTIGAÇÕES SOCIAIS DA AMÉRICA LATINA-CEISAL, 8., 20I6, Salamanca. Anais... Salamanca: jun./jul. 20I6b.

ARAÚJO FILHO, V. F. de; AZEVEDO ARAÚJO, M. A organização do governo Bolsonaro e a coordenação da crise sob a pandemia. In: FRESSATO, S. B. N. (Org.). Jorge, soou o alarme: a crise do capitalismo para além da pandemia. São Paulo: Perspectiva, 2020.

AVRITZER, L.; MARONA, M. A tensão entre soberania e instituições de controle na democracia brasileira. Dados, v. 6o, n. 2, p. 359-393, 2017.

BOSCHI, R. O executivo e a construção do estado no Brasil: do desmonte da era Vargas ao novo intervencionismo regulatório. In: VIANNA, L. W. (Org.). A democracia e os três poderes no Brasil. Rio de Janeiro: Editora UFMG; IUPERJ, 2002.

CARVALHO, J. M. Cidadania no Brasil. O longo caminho. Rio de Janeiro: Civilização Brasileira, 200I.

CALDEIRA, J. História da riqueza no Brasil. Rio de Janeiro: Estação Brasil, 2017.

COSTA, V. R. Origens do corporativismo brasileiro. In: BOSCHI, R. (Org.). Corporativismo e desigualdade. A construção do espaço público no Brasil. Rio de Janeiro: IUPERJ; Rio Fundo Editora, I99I. p. II3-I45. 
DINIZ, E.; BOCHI, R. O corporativismo na construção do espaço público. In: BOSCHI, R. (Org.). Corporativismo e desigualdade. A construção do espaço público no Brasil. Rio de Janeiro: IUPERJ; Rio Fundo Editora, I99I. p. II-30.

FAORO, R. Os donos do poder: formação do patronato político brasileiro. São Paulo: Globo, 2001.

FLORÊNCIO FILHO, M. A; ZANON, P. B. Arranjo institucional no âmbito da ENCCLA estratégia nacional de combate à corrupção e lavagem de dinheiro. DELICTAE: Revista de Estudos Interdisciplinares Sobre o Delito, v. 3, n. 5, p. 20I-235, 2018.

FONSECA, I. F. et al. Conhecimentos técnicos, políticas públicas e participação: o caso do conselho nacional do meio ambiente. Revista de Sociologia e Política; v. 20, n. 42, p. I83-I98, jun. 2012.

FONTAINHA, F.; EVELYN, A. Judiciário e crise política no Brasil hoje: do Mensalão à Lava Jato. Revista da Associação dos Antigos Alunos de Direito da Universidade Federal do Rio de Janeiro, v. I, n. I, 2019.

GUIMARÃES, C. Empresários, tipos de capitalismo e ordem política. DADOS, Rio de Janeiro, n. I4, p. 34-47, 1977.

HABERMAS, J. Direito e democracia: entre facticidade e validade. Rio de Janeiro: BTU, I997. $2 \mathrm{v}$.

IPEA. Conselhos nacionais - perfil e atuação dos conselheiros. Projeto Efetividade da Participação Social no Brasil. Brasília: IPEA, 2013.

KERCHE, F. O Ministério Público Brasileiro e seus mecanismos de accountability. In: ENCONTRO ANUAL DA ANPOCS, GT I2, 23., 1999, Caxambu. Anais... Caxambu: 1999.

KERCHE, F. O Ministério Público no Brasil: relevância, características e uma agenda para o futuro. Revista USP, n. IOI, p. II3-I2O, 2014.

KERCHE, F. Ministério Público, Lava Jato e Mãos Limpas: uma abordagem institucional. Lua Nova, n. I05, p. 255-286, 2018.

LAFORGE, G. The sum of its parts: coordinating Brazil's fight against corruption, 200320I6. Innovations for Successful Societies (Online), Princeton: Princeton University, 2017.

LINZ, J. Regimes autoritários. In: PINHEIRO, P. S. (Org.). O estado autoritário e movimentos populares. Rio de Janeiro: Paz e Terra, I980. p. II9-I88.

MARONA, M.; KERCHE, F. From the Banestado Case to Operation Car Wash: building an anti-corruption institutional framework in Brazil. Dados, v. 64, n. 3, 202I.

NICOLAU, J. História do voto no Brasil. Rio de Janeiro: Zahar, 2002.

NUNES, E. Gramática política do Brasil: clientelismo, corporativismo e insulamento burocrático. Rio de Janeiro: Zahar, 1997. 
NUNES, E.; RIBEIRO, L. M.; PEIXOTO, V. Agências reguladoras no Brasil. In: CINTRA, A. O.; AVELAR, L. (Org.). Sistema político brasileiro: uma introdução. Rio de Janeiro: Editora UNESP; Konrad Adenauer, 2007.

PRAÇA, S.; TAYLOR, M. Inching toward accountability: the evolution of Brazil's anticorruption institutions, 1985-2010. Latin American Politics and Society, v. 56, n. 2, p. 2748, 2014 .

RODRIGUES, F. A. Operação Lava-Jato: aprendizado institucional e ação estratégica na justiça criminal. 20I9. Dissertação (Mestrado) - Faculdade de Ciência Política, Universidade de São Paulo, São Paulo, 2019.

SÁ E SILVA, F. de. From Car Wash to Bolsonaro: law and lawyers in Brazil's illiberal turn (2014-2018). Journal of Law and Society, v. 47, n. SI, p. 90-IIO, 2020.

SANTOS, C. J. A gênese das grandes operações investigativas da Polícia Federal. Revista Brasileira de Ciências Policiais, v. 8, n. 2, p. II-68, 2017.

SANTOS, W. G. dos. Cidadania e justiça: a política social na ordem brasileira. Rio de Janeiro: Campus, 1979.

SANTOS, W. G. dos. Gênese e apocalipse: elementos para uma teoria da crise institucional latino-americana. Novos Estudos CEBRAP, n. 20, 1988.

STEPAN, A. Estado, corporativismo e autoritarismo. Rio de Janeiro: Paz e Terra, I980.

SINGER, A. A (falta de) base para o ensaio desenvolvimentista. In: SINGER, A.; LOUREIRO, I. (Orgs.). As contradições do lulismo: a que ponto chegamos? São Paulo: Boitempo, 20I6. p. 2I-54.

SOUZA, C. A que vieram as conferências nacionais? Uma análise dos objetivos dos processos realizados entre 2003 e 20IO. Texto para Discussão n. I7I8. Rio de Janeiro: IPEA, 2012.

SOUZA, M. do C. C. de. Estado e partidos políticos no Brasil (I930 a 1964). São Paulo: AlfaOmega, 1976.

VIANNA, L. W. Liberalismo e sindicato no Brasil. Rio de Janeiro: Paz e Terra, 1976.

VIANNA, L. W. et al. A judicialização da política e das relações sociais no Brasil. Rio de Janeiro: Revan, I999. 